Archived version from NCDOCKS Institutional Repository http://libres.uncg.edu/ir/asu/

Zeidell, Andrew M., Nathanael D. Cox, Shawn M. Huston, Jamie E. Rossi, Brian J. Landi, and Brad R. Conrad. 2015. "Cyclopentadienyliron Dicarbonyl Dimer Carbon Nanotube Synthesis.” Journal of Vacuum Science \& Technology B 33 (1): 011204. [ISSN: 1071-1023]. Version of record available at: http://dx.doi.org/10.1116/1.4904743

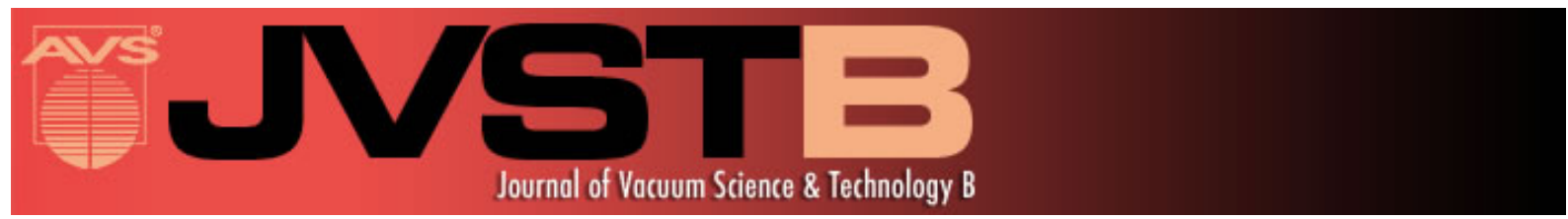

\title{
Cyclopentadienyliron dicarbonyl dimer carbon nanotube synthesis
}

Andrew M. Zeidell, Nathanael D. Cox, Shawn M. Huston, Jamie E. Rossi, Brian J. Landi, and Brad R. Conrad

Citation: Journal of Vacuum Science \& Technology B 33, 011204 (2015); doi: 10.1116/1.4904743

View online: http://dx.doi.org/10.1116/1.4904743

View Table of Contents: http://scitation.aip.org/content/avs/journal/jvstb/33/1?ver=pdfcov

Published by the AVS: Science \& Technology of Materials, Interfaces, and Processing

\section{Articles you may be interested in}

Effect of synthesis and acid purification methods on the microwave dielectric properties of single-walled carbon nanotube aqueous dispersions

Appl. Phys. Lett. 103, 133114 (2013); 10.1063/1.4823541

Effect of parameters on carbon nanotubes grown by floating catalyst chemical vapor deposition

AIP Conf. Proc. 1502, 242 (2012); 10.1063/1.4769148

Synthesis of multiwalled carbon nanotubes using RF-CCVD and a bimetallic catalyst AIP Conf. Proc. 1447, 275 (2012); 10.1063/1.4709986

Growth mechanism of multilayer-graphene-capped, vertically aligned multiwalled carbon nanotube arrays J. Vac. Sci. Technol. B 29, 061801 (2011); 10.1116/1.3644494

Synthesis and purification of single-walled carbon nanotubes by methane decomposition over iron-supported catalysts

J. Vac. Sci. Technol. A 24, 1314 (2006); 10.1116/1.2210943 


\title{
Cyclopentadienyliron dicarbonyl dimer carbon nanotube synthesis
}

Andrew M. Zeidell

Department of Physics and Astronomy, Appalachian State University, 525 Rivers Street, Boone, North Carolina 28608

Nathanael D. Cox

NanoPower Research Laboratory, Rochester Institute of Technology, Rochester, New York 14623 and

Department of Microsystems Engineering, Rochester Institute of Technology, Rochester, New York 14623

Shawn M. Huston ${ }^{\text {a) }}$

Department of Physics and Astronomy, Appalachian State University, 525 Rivers Street, Boone, North Carolina 28608

Jamie E. Rossi

Nanopower Research Laboratory, Rochester Institute of Technology, 160 Lomb Memorial Drive, Rochester, New York 14623

Brian J. Landi

NanoPower Research Laboratory, Rochester Institute of Technology, Rochester, New York 14623 and Department of Chemical Engineering, Rochester Institute of Technology, Rochester, New York 14623

Brad R. Conrad ${ }^{\text {b) }}$

Department of Physics and Astronomy, Appalachian State University, 525 Rivers Street, Boone, North Carolina 28608

(Received 8 September 2014; accepted 5 December 2014; published 23 December 2014)

\begin{abstract}
Well-aligned multiwalled carbon nanotubes (MWCNTs) were synthesized from a cyclopentadienyliron dicarbonyl dimer precursor using chemical vapor deposition and were systematically characterized over a variety of growth conditions. The injection volume of the precursor was found to affect both the MWCNT diameter distribution and the amount of residual iron catalyst found in the sample. Low injection volumes produced relatively low impurity samples. Synthesized materials contained as little as $2.47 \%$ catalyst impurity by weight and were grown without predeposition of catalyst materials onto the substrate, reducing the need for damaging purification processes necessary to remove the substrate. Scanning electron microscopy was used to investigate catalyst contamination, synthesized MWCNT diameters, and growth morphology. Additionally, transmission electron microscopy was employed to qualitatively examine nanotube wall formation and sidewall defects. Longer growth times resulted in a higher quality product. Raman spectroscopy was used in conjunction with thermogravimetric analysis to confirm sample quality. The relative efficacy of the precursor and material quality are evaluated. (C) 2014 American Vacuum Society. [http://dx.doi.org/10.1116/1.4904743]
\end{abstract}

\section{INTRODUCTION}

Research into the properties and synthesis of carbon nanotubes $(\mathrm{CNTs})^{1,2}$ has grown rapidly since their discovery in $1991 .{ }^{3}$ Unique CNT mechanical, electrical, and chemical properties have fueled the investigation of applications such as conductive additives in lithium ion batteries, ${ }^{4}$ electrodes in experimental supercapacitors, ${ }^{5}$ flexible alternatives to rare earth conductive films such as indium tin oxide, ${ }^{6,7}$ and components in biosensors ${ }^{8}$ and gas sensors. ${ }^{9}$ CNTs can be synthesized via the sublimation of carbon in an inert atmosphere using methods such as arc discharge, ${ }^{10}$ laser ablation, ${ }^{11}$ and concentrated sunlight, ${ }^{12}$ and chemical methods such as chemical vapor deposition (CVD) ${ }^{13,14}$ multistage reactors, ${ }^{15}$ and electrolysis. ${ }^{16}$ Aligned multiwalled carbon nanotube (MWCNT) arrays are advantageous in applications such as electrodes in organic solar cells. ${ }^{7}$ Aligned arrays provide

\footnotetext{
${ }^{a)}$ Current address: Department of Physics, Radford University, 131 Curie Building, Radford, VA 24142.

b)Electronic mail: conradbr@appstate.edu
}

better charge separation than random CNT networks ${ }^{17}$ as well as improve their mechanical and electrical properties. ${ }^{18}$

One of the most promising synthesis techniques for the production of large scale quantities of aligned MWCNTs is the injection CVD method. Injection CVD is performed by injecting a carbon source into a furnace with predeposited catalyst on a substrate, with the most common types of metal catalyst particle being $\mathrm{Fe}, \mathrm{Co}$, and $\mathrm{Ni}$; though $\mathrm{Cu}, \mathrm{Au}, \mathrm{Ag}$, $\mathrm{Pt}$, and Pd also catalyze MWCNT growth. ${ }^{19}$ Prepatterned substrates enable aligned MWCNT growth and diameter tuning by controlling catalyst site size and distribution. ${ }^{14,20}$ However, catalyst sites can eventually deactivate through the continuous deposition of pyrolyzed hydrocarbons ${ }^{21}$ and Ostwald ripening, ${ }^{22,23}$ thus samples often require damaging, ${ }^{24-26}$ multistep purification processes employing hazardous chemicals to remove catalyst particles and substrate. ${ }^{27}$ The ability to synthesize aligned MWCNT arrays with low levels of initial contaminants is very important, as it would reduce the number of steps before utilizing the product and decrease the amount of damage and waste caused by 
purification processes. By employing the floating catalyst method of injection CVD, a precursor ${ }^{28}$ serves as both a potential carbon source ${ }^{29}$ and the catalyst source, which eliminates the need for a prepatterned substrate. This allows for continuous growth by constant deposition of new catalyst particles, which reduces the catalyst deactivation problems encountered with a prefabricated substrate, potentially making this growth method suitable for industry applications. While convenient, in situ formation of catalyst particles produces a broad size distribution of carbon nanotubes ${ }^{15}$ and this distribution will vary with process conditions, such as injection volume, as this will affect the CNT diameter distribution.

The most popular precursors for floating catalyst CVD systems are metallocenes such as ferrocene, nickelocene, and cobaltocene. ${ }^{30}$ Synthesis via ferrocene is versatile and useful for creating a large range of nanostructures, such as single, double, and multi-walled CNTs as well as branched CNTs and carbon nanospheres ${ }^{29}$ and has proven to produce well aligned nanotubes with a residual catalyst content of about $10 \%$ by weight. ${ }^{31}$ The work presented here used cyclopentadienyliron dicarbonyl dimer $\left[\mathrm{Fe}_{2}\left(\mathrm{C}_{5} \mathrm{H}_{5}\right)_{2}(\mathrm{CO})_{4}\right]$ dissolved in toluene, where the $\mathrm{Fe}_{2}\left(\mathrm{C}_{5} \mathrm{H}_{5}\right)_{2}(\mathrm{CO})_{4}$ served as the feedstock and iron catalyst source, and the toluene provided additional carbon during the reaction. This precursor has been shown to synthesize MWCNTs with a low as-produced residual catalyst ${ }^{32}$ and has been used to grow $\mathrm{Fe}$ filled MWCNTs. ${ }^{33}$ While there is Raman spectra evidence ${ }^{32}$ that some single-walled CNTs are formed from this precursor, the majority of CNT formation is not single-walled. Since this method of catalyst formation will most likely produce a broad distribution of iron particle sizes ${ }^{34}$ through a nanoparticle agglomeration process, a broad distribution of CNT diameters and wall numbers is expected, in comparison to selective wall growth techniques. ${ }^{15}$

In this study, the effect of total precursor injection volume on product quality, in terms of amorphous carbon content and residual catalyst, is studied. The $\mathrm{Fe}_{2}\left(\mathrm{C}_{5} \mathrm{H}_{5}\right)_{2}(\mathrm{CO})_{4}$ precursor produces aligned MWCNTs with levels of residual catalyst lower than the aforementioned precursors, and the incorporation of both ligand and ring structures in the precursor has the potential to be used to dope CNTs with heteroatoms and improve synthesis, making it a potential choice for creating new families of floating catalyst precursors. ${ }^{28}$ Using this precursor, aligned MWCNTs can be easily produced without any substrate prefabrication and with a high initial purity.

\section{EXPERIMENT}

MWCNTs were fabricated using a Nanotech Innovations SSP-354 atmospheric pressure injection CVD reactor. Anhydrous toluene solutions of the catalyst, cyclopentadienyliron dicarbonyl dimer $\left[\mathrm{Fe}_{2}\left(\mathrm{C}_{5} \mathrm{H}_{5}\right)_{2}(\mathrm{CO})_{4},(0.10 \pm 0.05)\right.$ $\mathrm{M}$ ], were injected through a 26 gauge needle into the preheat zone of the reactor furnace. Solution was injected at a rate of $7.5 \mathrm{ml} / \mathrm{h}$ for all reactions and controlled by a $\mathrm{kdScientific}$ KDS-100 syringe pump. Precursor injection volumes of 7.5,
$11.25,15,18.75$, and $22.5 \mathrm{ml}$ were examined. The preheat zone of the furnace was held at $215 \pm 1{ }^{\circ} \mathrm{C}$, which is lower than the boiling point of the toluene solvent (i.e., $231.1^{\circ} \mathrm{C}$ ) and above the melting point of the precursor (i.e., $194^{\circ} \mathrm{C}$ ). Forming gas, which contains a mixture of $\mathrm{H}_{2} / \mathrm{Ar}(5 \% / 95 \%$, respectively), was flowed through the quartz reaction chamber at 1 LPM, which carried the precursor to the high temperature zone of the furnace that was kept at $700 \pm 1{ }^{\circ} \mathrm{C}$. MWCNT samples were collected from inside the hightemperature reaction zone using a spatula and were exfoliated from the reactor walls in the form of flakes. Raw MWCNTs were characterized with field emission scanning electron microscopy (SEM) using a Hitachi S-4000 instrument with an accelerating voltage of $5.0 \mathrm{kV}$. Raman spectroscopy was performed using a Jobin Yvon LabRam spectrometer with an excitation energy of $1.96 \mathrm{eV}$, and thermogravimetric analysis (TGA) data were acquired using a Q5000 IR thermogravimetric analyzer, using measurement conditions similar to the work of Harris et al. ${ }^{32}$ As-produced MWCNTs were dispersed in dimethylformamide (SigmaAldrich) via sonication for $30 \mathrm{~min}$, and were cast on a 200 mesh $\mathrm{Cu}$ transmission electron microscope (TEM) grids (PELCO; Ted Pella, INC). The mounted samples were investigated using a JEOL JEM-1400 TEM with a beam energy of $120 \mathrm{keV}$.

\section{RESULTS AND DISCUSSION}

MWCNT samples were produced using various injection volumes $(7.5,11.25,15,18.75$, and $22.5 \mathrm{ml})$ of the $\mathrm{Fe}_{2}\left(\mathrm{C}_{5} \mathrm{H}_{5}\right)_{2}(\mathrm{CO})_{4}$ precursor and grown on the interior walls of the quartz reactor tube in place of a prefabricated substrate. SEM imaging of as-produced samples showed successful MWCNT growth with high levels of nearest neighbor alignment in reactions using higher injection volumes. SEM images showing the morphology of the MWCNTs synthesized with precursor injection volumes of $7.5,15$, and $22.5 \mathrm{ml}$ are displayed in Fig. 1. The local alignment and density of the MWCNT changes from randomly aligned MWCNT bundles to uniformly aligned arrays between the 7.5 and $15 \mathrm{ml}$ injection volumes. The alignment does not improve after the $15 \mathrm{ml}$ reaction, owing to the decrease in MWCNT diameter and increase in the total number of MWCNTs, which causes the bundles to align. The outer diameters of MWCNTs were measured via SEM, and ranged from 7 to $130 \mathrm{~nm}$, which is similar to MWCNT diameters synthesized with other metallocenes. ${ }^{35,36}$ Diameter distributions were obtained by measuring the diameters of at least 100 MWCNTs from each growth condition as determined by the global diameter assessment tools using ImageJ (Ref. 37) from multiple SEM and TEM images. The $15 \mathrm{ml}$ injection volume yielded the most uniformly weighted diameter distribution, which is desirable for applications that the produced MWCNTs would share similar properties in the array.

MWCNTs were imaged with TEM, and inclusion of nanorods, possibly of the iron catalyst material, was observed in some MWCNTs [Figs. 2(a) and 2(b)]. Previous 

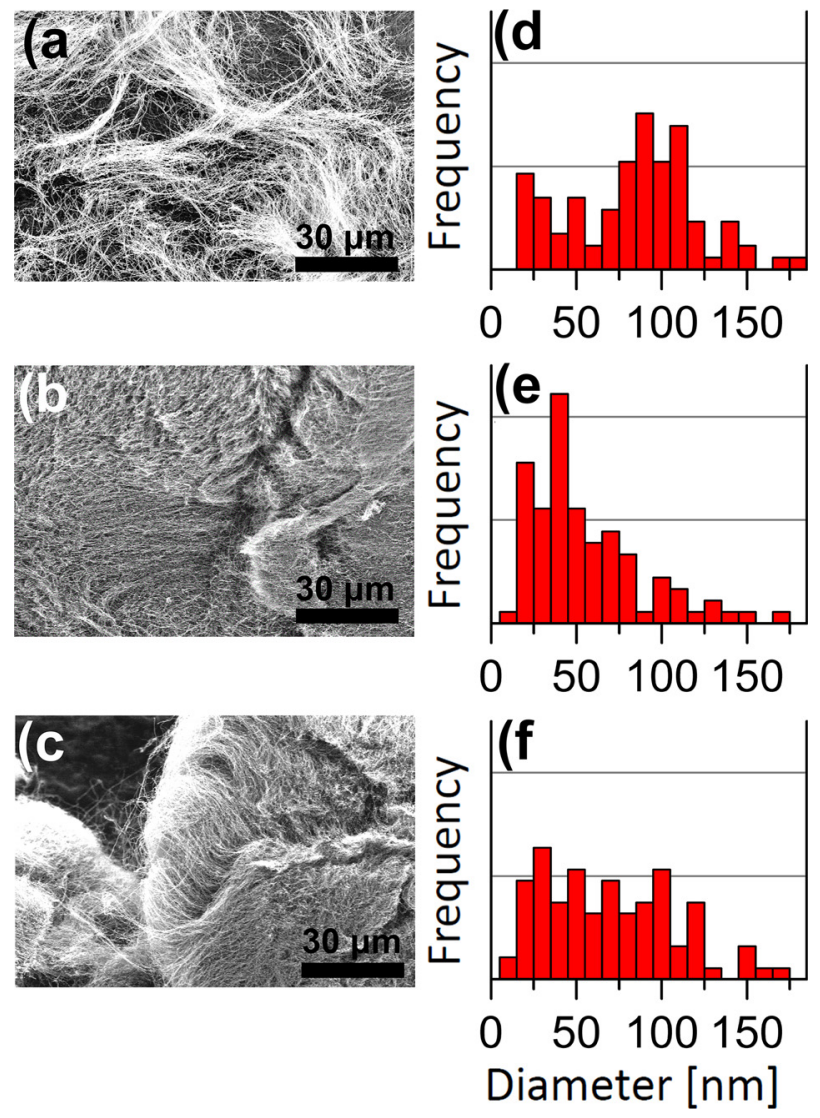

FIG. 1. (Color online) $128 \mu \mathrm{m} \times 98 \mu \mathrm{m}$ SEM micrographs of MWCNT growth with varied precursor injection volumes of (a) $7.5 \mathrm{ml}$, (b) $15 \mathrm{ml}$, and (c) $22.5 \mathrm{ml}$. Note the apparent change in growth alignment and density between (a) and (b). Corresponding diameter distributions of MWCNT are displayed below each micrograph, which were compiled from sampling greater than 100 MWCNTs from growth conditions using (d) $7.5 \mathrm{ml}$, (e) $15 \mathrm{ml}$, and (f) $22.5 \mathrm{ml}$ of the $\mathrm{Fe}_{2}\left(\mathrm{C}_{5} \mathrm{H}_{5}\right)_{2}(\mathrm{CO})_{4}$ precursor.

experiments using this precursor for CVD growth also showed iron nanorods trapped inside synthesized MWCNTs, as determined via energy dispersive $\mathrm{x}$-ray spectroscopy. ${ }^{33}$ Nanotubes exhibited sidewall defects, such as buckling and folding, along their lengths in all growths, as seen in Figs. 2(a) and 2(c). Thick MWCNTs are very prone to develop these deformations when subjected to stress due to mechanical grinding and sonication, ${ }^{38,39}$ though whether the deformations were caused during sample removal or sonication is unknown. TEM analysis of the overall sample set showed similar catalyst encapsulations and sidewall defects in all injection volumes.

Additional characterization of the samples was performed using thermogravimetric analysis in air, providing a measure of the residual catalyst in the samples as well as the oxidation temperature of the samples, as seen in Fig. 3. The TGA data showed maximum weight loss, as seen in the first derivative of the weight loss with respect to temperature (dashed line of Fig. 3), between 617 and $632^{\circ} \mathrm{C}$ for all samples. This is within the known decomposition temperature range of MWCNTs (Refs. 40 and 41) and indicates that the majority of the sample mass existed as carbon rather than catalyst particles. However, the amount of amorphous carbon versus MWCNTs cannot be deconvolved from the TGA signal,
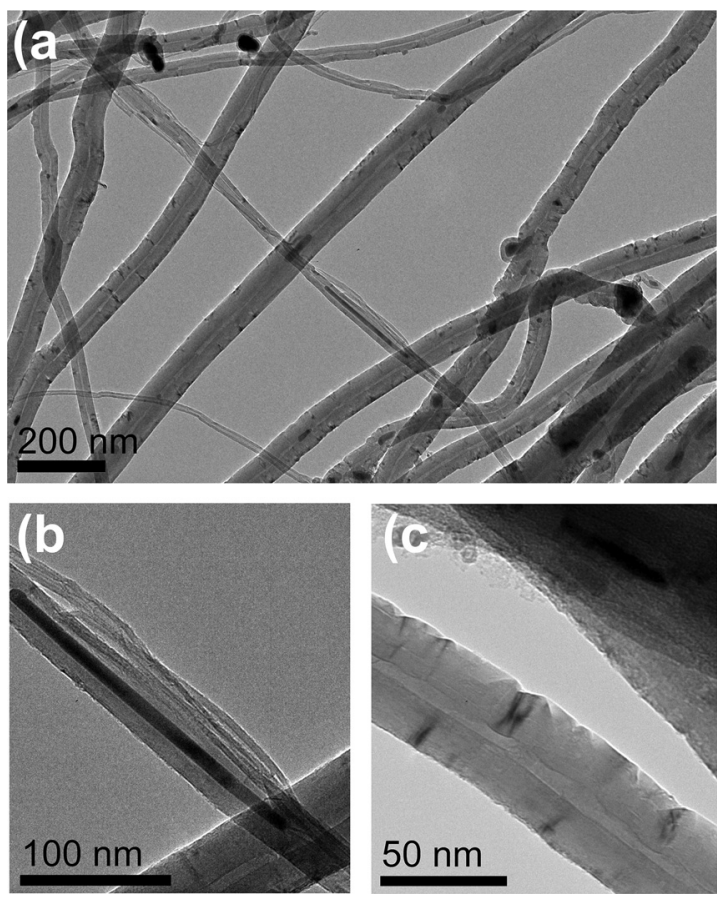

FIG. 2. (a) $1623 \mathrm{~nm} \times 1082 \mathrm{~nm}$ TEM image of MWCNTs synthesized with $15 \mathrm{ml}$ of the precursor. (b) A $250 \mathrm{~nm} \times 270 \mathrm{~nm}$ TEM image of encapsulated nanorod of catalyst material, as seen in the center of image (a), and (c) a $150 \mathrm{~nm} \times 160 \mathrm{~nm}$ image displaying sidewall defects, as representative of all reactions, in a MWCNT synthesized with $7.5 \mathrm{ml}$ of the precursor.

since the decomposition of MWCNTs and carbon nanoparticles occur at nearly the same temperature. ${ }^{40}$ The sample with the least residual iron was the $7.5 \mathrm{ml}$ reaction, at $2.47 \%$ catalyst impurity by weight, which is low in comparison to the residual catalyst observed in following reactions. This reaction had the largest observed diameters, as seen in Fig. 1(d), meaning that more carbon was trapped in many layered, large diameter MWCNTs, making the ratio of carbon to catalyst larger than in successive reactions where the rate of catalyst deactivation may be higher; thus, more carbon was formed as MWCNTs rather than being swept into the exhaust during the reaction. The alignment of MWCNTs in this reaction was also less orderly than in successive

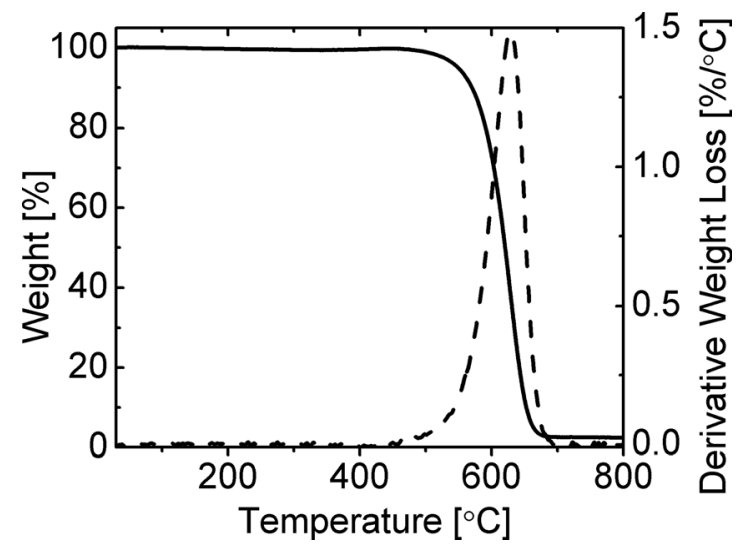

FIG. 3. Thermogravimetric analysis of the $7.5 \mathrm{ml}$ MWCNT growth sample. The solid black line is the weight percent as a function of temperature, and the dashed black line is the derivative of the weight percent, the peak of which occurs at $630^{\circ} \mathrm{C}$. This sample had a residual Fe catalyst by weight of $2.47 \%$. 
reactions, existing as bundles rather than aligned arrays, as seen in Fig. 1(a). Reactions with higher injection volumes had residual catalyst varying from 6.0 to $9.5 \mathrm{wt}$. \% and also showed more organized alignment, leading to the conclusion that for aligned MWCNT arrays that this amount of residual catalyst is normal for this precursor. Increased iron content and CNT alignment can be partially attributed to Ostwald ripening, as catalyst particle size and distribution will be effected by injection volume. ${ }^{22,23}$ Other metallocene precursors can provide a residual catalyst content of anywhere from $7 \%$ to $22 \%$ by weight. ${ }^{42,43}$ The residual catalyst impurity for each sample, as well as the temperature of maximum weight loss, can be found in Table I. TGA curves for the other samples may be found in the supplementary material. ${ }^{44}$

Raman spectroscopy was used to further characterize each sample and provide information about the quality of the synthesized nanotubes, as has been reported in detail elsewhere. ${ }^{45-47}$ It is generally accepted that the ratio of D and G bands of Raman spectroscopy is a quality parameter for CNTs. ${ }^{47,48}$ The Raman spectra in Fig. 4 show the characteristic MWCNT peaks at the D, G, and $\mathrm{G}^{\prime}$ bands $(\sim 1350$, $\sim 1580$, and $\sim 2700 \mathrm{~cm}^{-1}$, respectively). ${ }^{41}$ The $\mathrm{D}$ band corresponds to disordered amorphous carbon with $\mathrm{sp} 3$ bonding double resonance affects in sp2 carbon, ${ }^{49}$ the $\mathrm{G}$ band results from vibrations of graphitic carbon, and the $\mathrm{G}^{\prime}$ band represents the long-range order of the sample and is caused by two-phonon, second order scattering. ${ }^{50,51}$ Individual spectra of each sample may be found in higher resolution in the supplementary material. ${ }^{44}$ The ratio of peak intensities of the Raman D and G peaks (ID/IG ratio) is used often as a measure of the relative quality of MWCNT formation, ${ }^{48,52}$ since it is the ratio of amorphous carbon to the degree of structural order of the sample. This ratio ranged from 0.65 to 0.57 , and in general showed a trend toward higher sample quality with increasing injection volume for our samples, as seen in Fig. 5. The lowest ratio corresponds to the $22.5 \mathrm{ml}$ growth, showing that this sample had the lowest ratio of amorphous carbon with respect to the sample crystallinity.

\section{SUMMARY AND CONCLUSIONS}

The $\mathrm{Fe}_{2}\left(\mathrm{C}_{5} \mathrm{H}_{5}\right)_{2}(\mathrm{CO})_{4}$ precursor used in this study produced MWCNTs with concentrations of residual catalyst impurity as little as $2.47 \%$ by weight. Alignment of MWCNT's has been shown and lower injection volumes produced relatively lower impurity samples. MWCNTs were successfully

TABLE I. Maximum weight loss found from peak of the derivative of TGA curve and residual catalyst impurity by weight for each injection volume.

\begin{tabular}{lcc}
\hline \hline $\begin{array}{l}\text { Injection volume }(\mathrm{ml}) \\
( \pm 0.01 \mathrm{ml})\end{array}$ & $\begin{array}{c}\text { Maximum weight } \\
\text { loss temperature } \\
\left({ }^{\circ} \mathrm{C}\right)\left( \pm 1{ }^{\circ} \mathrm{C}\right)\end{array}$ & $\begin{array}{c}\text { Residual Fe catalyst } \\
\text { by weight }(\%) \\
( \pm 0.01 \%)\end{array}$ \\
\hline 7.50 & 630 & 2.47 \\
11.25 & 618 & 6.04 \\
15.00 & 627 & 6.90 \\
18.75 & 623 & 9.51 \\
22.50 & 632 & 6.71 \\
\hline \hline
\end{tabular}

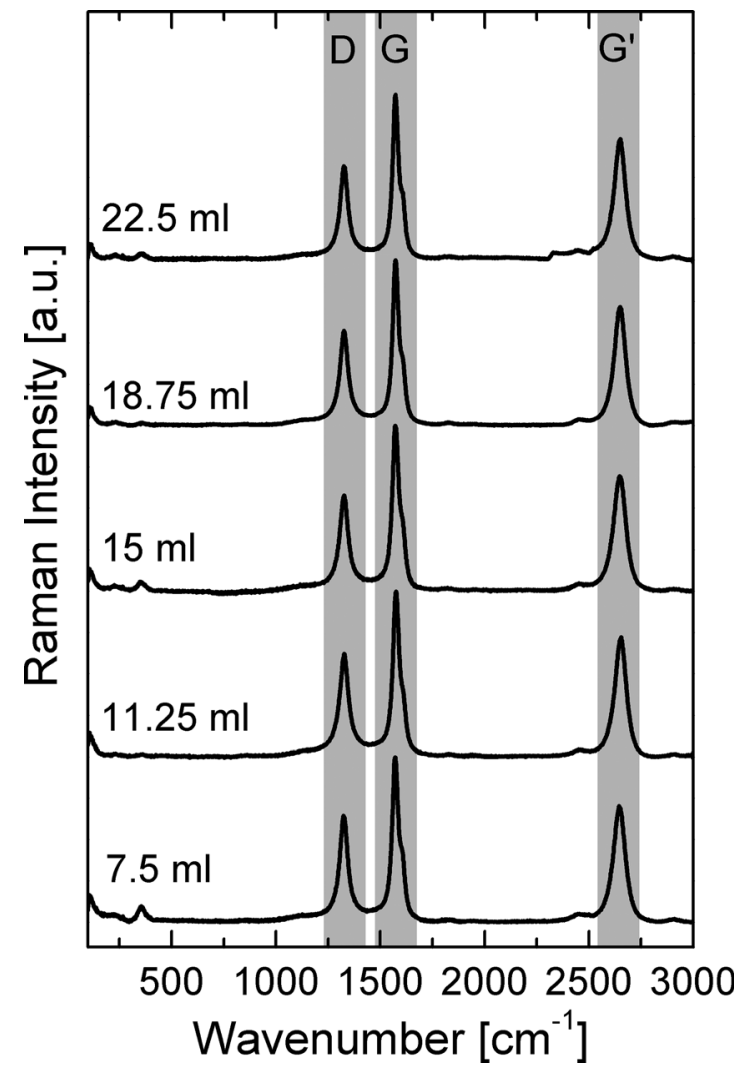

FIG. 4. Raman spectra for sample set of MWCNTs synthesized from injection volumes 7.5 to $22.5 \mathrm{ml}$. Incident laser energy was $1.96 \mathrm{eV}$. D, G, and $\mathrm{G}^{\prime}$ bands are highlighted and successive data offset applied for comparison. Of particular note is the decrease in $D$ peak relative to the $G$ and $G^{\prime}$ peaks with increasing injection volume.

grown without a prefabricated substrate and with preferential alignment. The ratio of amorphous carbon to structural order of the as-produced MWCNTs decreased with injection volume as observed by Raman spectroscopy, implying the product was better formed and contained less carbonaceous impurity with increased injection volume. The most uniformly weighted diameter distribution of MWCNTs was found in the $15 \mathrm{ml}$ reaction. However, for the 18.75 and $22.5 \mathrm{ml}$ injection volumes, the diameters observed had a more homogeneous diameter distribution rather than being

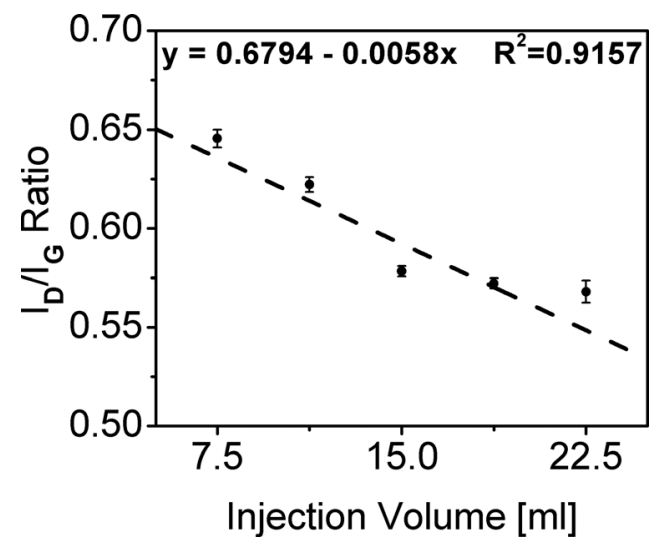

FIG. 5. Plot of successive ID/IG ratios as determined by Raman spectroscopy for each injection volume. Error bars represent variability in peak ratios due to the resolution of the Raman system. 
weighted toward smaller diameters. MWCNTs existed as large, randomly aligned bundles for lower injection volumes, but became more uniformly aligned in reactions observed with injection volumes past $15 \mathrm{ml}$. Using this precursor, MWCNTs can be easily produced without any substrate prefabrication, allowing for continuous growth and reducing the need for the potentially damaging, multistep purification processes necessary to remove the substrate, potentially making this growth method suitable for industry applications.

\section{ACKNOWLEDGMENTS}

The authors from RIT gratefully acknowledge funding from the U.S. Government through the Defense Threat Reduction Agency (DTRA) under Grant HDTRA-1-10-10122. This material is based upon work funded in whole or in part by the U.S. Government, and any opinions, findings, conclusions, or recommendations expressed in this material are those of the author(s) and do not necessarily reflect the views of the U.S. Government. Appalachian State authors gratefully acknowledge funding from the National Space Grant College and Fellowship Program, the NC Space Grant Consortium, and the Appalachian State Office of Student Research. Appalachian State University authors would also like to thank G. Hou of the William C. and Ruth Ann Dewel Microscopy Facility at AppState providing TEM micrographs of the nanotubes, Phillip Russell in the Appalachian State Physics and Astronomy department for providing SEM micrographs of the nanotubes, as well as Cortney Bougher for comments that greatly improved the manuscript.

${ }^{1}$ H. Li, C. Xu, N. Srivastava, and K. Banerjee, IEEE Trans. Electron Devices 56, 1799 (2009).

${ }^{2}$ Y. C. Lan, Y. Wang, and Z. F. Ren, Adv. Phys. 60, 553 (2011).

${ }^{3}$ S. Iijima, Nature 354, 56 (1991).

${ }^{4}$ B. J. Landi, M. J. Ganter, C. D. Cress, R. A. DiLeo, and R. P. Raffaelle, Energy Environ. Sci. 2, 638 (2009).

${ }^{5}$ Q. Y. Li, Z. S. Li, L. Lin, X. Y. Wang, Y. F. Wang, C. H. Zhang, and H. Q. Wang, Chem. Eng. J. 156, 500 (2010).

${ }^{6}$ J. M. Schnorr and T. M. Swager, Chem. Mater. 23, 646 (2011).

${ }^{7}$ K. Sears, G. Fanchini, S. E. Watkins, C. P. Huynh, and S. C. Hawkins, Thin Solid Films 531, 525 (2013).

${ }^{8}$ K. Balasubramanian and M. Burghard, Anal. Bioanal. Chem. 385, 452 (2006).

${ }^{9}$ T. Zhang, S. Mubeen, N. V. Myung, and M. A. Deshusses, Nanotechnology 19, 332001 (2008).

${ }^{10}$ T. W. Ebbesen and P. M. Ajayan, Nature 358, 220 (1992).

${ }^{11}$ T. Guo, P. Nikolaev, A. G. Rinzler, D. Tomanek, D. T. Colbert, and R. E. Smalley, J. Phys. Chem. 99, 10694 (1995).

${ }^{12}$ D. Laplaze, P. Bernier, W. K. Maser, G. Flamant, T. Guillard, and A. Loiseau, Carbon 36, 685 (1998).

${ }^{13}$ M. Joseyacaman, M. Mikiyoshida, L. Rendon, and J. G. Santiesteban, Appl. Phys. Lett. 62, 202 (1993).

${ }^{14}$ C. L. Cheung, A. Kurtz, H. Park, and C. M. Lieber, J. Phys. Chem. B 106, 2429 (2002).

${ }^{15}$ W. H. Chiang and R. M. Sankaran, J. Phys. Chem. C 112, 17920 (2008).

${ }^{16}$ W. K. Hsu, J. P. Hare, M. Terrones, H. W. Kroto, D. R. M. Walton, and P. J. F. Harris, Nature 377, 687 (1995).
${ }^{17}$ Z. B. Yang, T. Chen, R. X. He, G. Z. Guan, H. P. Li, L. B. Qiu, and H. S. Peng, Adv. Mater. 23, 5436 (2011).

${ }^{18}$ X. M. Sun, T. Chen, Z. B. Yang, and H. S. Peng, Acc. Chem. Res. 46, 539 (2013).

${ }^{19}$ M. Kumar and Y. Ando, J. Nanosci. Nanotechnol. 10, 3739 (2010).

${ }^{20}$ G. D. Nessim, A. J. Hart, J. S. Kim, D. Acquaviva, J. H. Oh, C. D. Morgan, M. Seita, J. S. Leib, and C. V. Thompson, Nano Lett. 8, 3587 (2008).

${ }^{21}$ F. Danafar, A. Fakhru'1-Razi, M. A. M. Salleh, and D. R. A. Biak, Chem. Eng. J. 155, 37 (2009).

${ }^{22}$ P. B. Amama, C. L. Pint, L. McJilton, S. M. Kim, E. A. Stach, P. T. Murray, R. H. Hauge, and B. Maruyama, Nano Lett. 9, 44 (2009).

${ }^{23}$ S. M. Kim, C. L. Pint, P. B. Amama, D. N. Zakharov, R. H. Hauge, B. Maruyama, and E. A. Stach, J. Phys. Chem. Lett. 1, 918 (2010).

${ }^{24}$ C. Laurent, A. Peigney, and A. Rousset, J. Mater. Chem. 8, 1263 (1998).

${ }^{25}$ K. Hernadi, A. Siska, L. Thien-Nga, L. Forro, and I. Kiricsi, Solid State Ionics 141, 203 (2001).

${ }^{26}$ V. Datsyuk, M. Kalyva, K. Papagelis, J. Parthenios, D. Tasis, A. Siokou, I. Kallitsis, and C. Galiotis, Carbon 46, 833 (2008).

${ }^{27}$ K. Hernadi, A. Fonseca, J. B. Nagy, D. Bernaerts, J. Riga, and A. Lucas, Synth. Met. 77, 31 (1996).

${ }^{28}$ A. F. Hepp and J. D. Harris, U.S. patent 7,763,230 B2 (9 November 2006).

${ }^{29}$ V. O. Nyamori, S. D. Mhlanga, and N. J. Coville, J. Organomet. Chem. 693, 2205 (2008).

${ }^{30}$ R. Sen, A. Govindaraj, and C. N. R. Rao, Chem. Phys. Lett. 267, 276 (1997).

${ }^{31}$ C. J. Lee, S. C. Lyu, H. W. Kim, C. Y. Park, and C. W. Yang, Chem. Phys. Lett. 359, 109 (2002).

${ }^{32}$ J. D. Harris, R. P. Raffaelle, T. Gennett, B. J. Landi, and A. E. Hepp, Mater. Sci. Eng., B 116, 369 (2005).

${ }^{33}$ C. Muller, A. Leonhardt, S. Hampel, and B. Buchner, Phys. Status Solidi B 243, 3091 (2006).

${ }^{34}$ M. A. Tenhover, R. S. Henderson, and R. K. Grasselli, U.S. patent 4,537,624 (3 July 1985).

${ }^{35}$ M. Mayne, N. Grobert, M. Terrones, R. Kamalakaran, M. Ruhle, H. W. Kroto, and D. R. M. Walton, Chem. Phys. Lett. 338, 101 (2001).

${ }^{36}$ S. B. Sinnott, R. Andrews, D. Qian, A. M. Rao, Z. Mao, E. C. Dickey, and F. Derbyshire, Chem. Phys. Lett. 315, 25 (1999).

${ }^{37}$ C. A. Schneider, W. S. Rasband, and K. W. Eliceiri, Nat. Methods 9, 671 (2012).

${ }^{38}$ J. Hilding, E. A. Grulke, Z. G. Zhang, and F. Lockwood, J. Dispersion Sci. Technol. 24, 1 (2003).

${ }^{39}$ A. Lucas, C. Zakri, M. Maugey, M. Pasquali, P. van der Schoot, and P. Poulin, J. Phys. Chem. C 113, 20599 (2009).

${ }^{40}$ L. S. K. Pang, J. D. Saxby, and S. P. Chatfield, J. Phys. Chem. 97, 6941 (1993).

${ }^{41}$ J. H. Lehman, M. Terrones, E. Mansfield, K. E. Hurst, and V. Meunier, Carbon 49, 2581 (2011).

${ }^{42}$ M. Cinke, J. Li, B. Chen, A. Cassell, L. Delzeit, J. Han, and M. Meyyappan, Chem. Phys. Lett. 365, 69 (2002).

${ }^{43}$ R. Andrews, D. Jacques, D. Qian, and E. C. Dickey, Carbon 39, 1681 (2001).

${ }^{44}$ See supplementary material at http://dx.doi.org/10.1116/1.4904743 for additional thermogravimetric analysis and Raman spectrographs of MWCNT growth samples.

${ }^{45}$ E. F. Antunes, A. O. Lobo, E. J. Corat, V. J. Trava-Airoldi, A. A. Martin, and C. Verissimo, Carbon 44, 2202 (2006).

${ }^{46}$ M. Stadermann et al., Nano Lett. 9, 738 (2009).

${ }^{47}$ C. Singh, M. S. Shaffer, and A. H. Windle, Carbon 41, 359 (2003).

${ }^{48}$ R. A. DiLeo, B. J. Landi, and R. P. Raffaelle, J. Appl. Phys. 101, 64307 (2007).

${ }^{49}$ R. Saito, A. Jorio, A. G. Souza, G. Dresselhaus, M. S. Dresselhaus, and M. A. Pimenta, Phys. Rev. Lett. 88, 027401 (2001).

${ }^{50}$ Y. Wang, D. C. Alsmeyer, and R. L. Mccreery, Chem. Mater. 2, 557 (1990).

${ }^{51}$ R. Saito et al., New J. Phys. 5, 157 (2003).

${ }^{52}$ M. Endo, Y. A. Kim, Y. Fukai, T. Hayashi, M. Terrones, H. Terrones, and M. S. Dresselhaus, Appl. Phys. Lett. 79, 1531 (2001). 